ENTREVISTA

\title{
HABILIDADES SOCIOEMOCIONAIS NA EDUCAÇÃO ATUAL
}

O novo contexto em que as relações entre professores, alunos e instituições de ensino se desenvolvem com a mediação das tecnologias da educação a distância e a expectativa pela volta às aulas presenciais após a quarentena fazem refletir sobre uma questão que já vinha sendo apontada como fundamental para a formação de pessoas e profissionais no século XXI antes mesmo da pandemia: a importância do desenvolvimento de habilidades socioemocionais. Nesse sentido, o Instituto Ayrton Senna vem ocupando posição de liderança, colocando, na pauta dos sistemas de ensino de todo o país, essa mudança de mentalidade para a formação de um o novo paradigma educacional. Esta entrevista busca elucidar o impacto das competências socioemocionais nos processos de ensino, aprendizagem e formação para um novo mercado de trabalho.

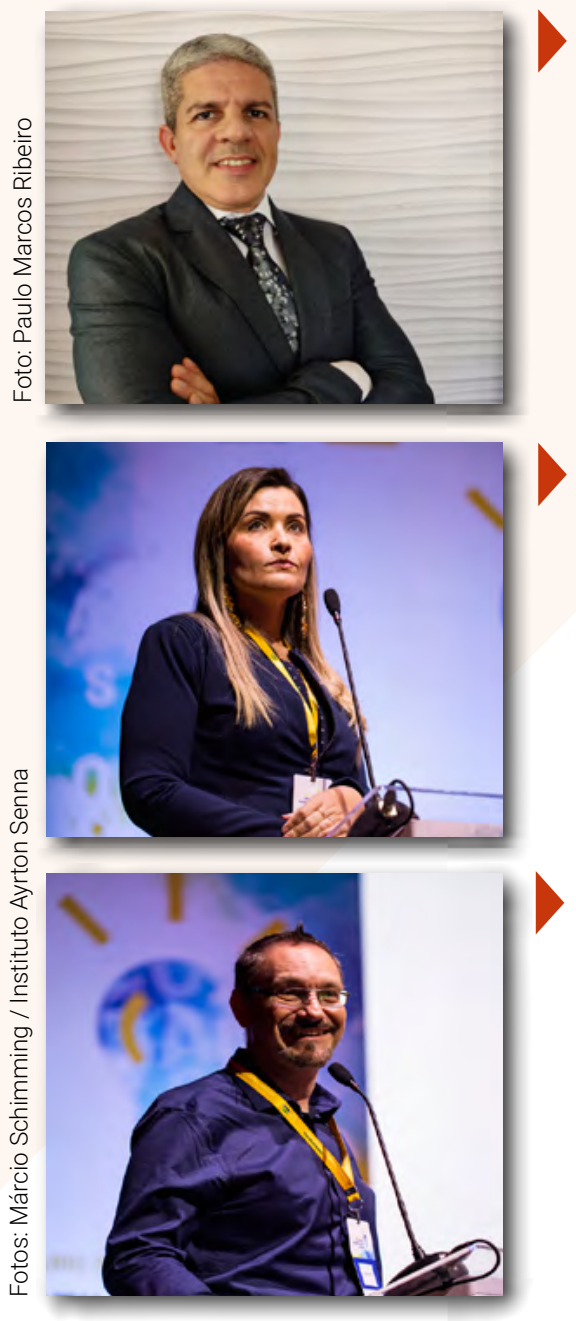

\section{Anderson Córdova Pena}

Psicólogo. Doutor em Educação, Políticas Públicas e Avaliação Educacional. Responsável Técnico pelo Desenvolvimento de Projetos da Gerência de Desenvolvimento Educacional do Senac, Departamento Nacional. E-mail: anderson.pena@senac.br

\section{Gisele Alves}

Gerente do eduLab21, Laboratório de Ciências para a Educação do Instituto Ayrton Senna (IAS). Psicóloga. Mestra em Psicologia pelo Programa de Pós-graduação stricto sensu da Universidade São Francisco, com ênfase em Avaliação Psicológica.

E-mail: gmizuta@ias.org.br

\section{Ricardo Primi}

Membro do Conselho Científico do eduLab21, Laboratório de Ciências para a Educação do IAS. Psicólogo. Professor no Programa de Pós-graduação stricto sensu da Universidade São Francisco. E-mail: rprimi@mac.com 


\section{ACP - 0 que podemos entender por habilidades socioemocionais? Quais são essas ha- bilidades?}

GA e RP - As habilidades socioemocionais são um conjunto de características pessoais no âmbito das emoções e relações sociais em sua interação com pensamento e inteligência em três núcleos centrais: regulação e controle voluntário do comportamento e motivação; regulação emocional; e habilidades interpessoais. Elas possibilitam a mobilização, a articulação e a prática de conhecimentos, valores e atitudes necessários para se relacionar com os outros e consigo mesmo, estabelecer e atingir objetivos, assim como enfrentar diferentes situações de maneira mais criativa e construtiva. Além disso, manifestam-se na forma de padrões de pensamentos, sentimentos e comportamentos e são moldáveis, ou seja, podem ser aprendidas em contextos formais e informais de aprendizagem. Também podem exercer influência sobre diversos resultados positivos na vida das pessoas, em diferentes fases do desenvolvimento, contribuindo para a promoção do sucesso escolar e na vida futura dos estudantes, sua saúde e bem-estar, por exemplo.

A base conceitual-teórica que possui sustentação empírica mais consistente na literatura propõe uma taxonomia conceitual integrativa das habilidades socioemocionais, a qual favorece uma linguagem comum para unificá-las e organizá-las em cinco grupos. Essa taxonomia é objeto de estudo em diversas organizações que atuam na educação, como a Organização para a Cooperação e Desenvolvimento Econômico (OCDE), o Collaborative for Academic, Social, and Emotional Learning (CASEL) e o Instituto Ayrton Senna (IAS).

A partir dos estudos fomentados pelo IAS, em conjunto com diversas redes de ensino público do país, foi possível identificar quais características socioemocionais podem ser desenvolvidas na escola sob a perspectiva da educação integral. Assim, essas características socioemocionais foram organizadas em cinco fatores e 17 facetas. Um dos fatores é a Abertura ao Novo, composta pelas habilidades (ou facetas): Curiosidade para aprender, Imaginação criativa e Interesse artístico; em segundo, a Autogestão, cujas habilidades denominadas são Determinação, Persistência, Foco, Responsabilidade e Organização; o terceiro fator, Engajamento com os Outros, identifica-se por Iniciativa social, Assertividade, e Entusiasmo; o quarto fator é a Amabilidade (Empatia, Respeito e Confiança); e o quinto fator é a Resiliência Emocional (composto pelas habilidades de autoconfiança, tolerância ao estresse e tolerância à frustração).

\section{ACP- Em que medida as habilidades socioemocionais podem ser ensinadas em con- textos escolares, inclusive para jovens e adultos?}

GA e RP - As evidências disponíveis na literatura têm demonstrado que a aprendizagem socioemocional ocorre desde a infância, passando pela adolescência e fase adulta até a velhice, sendo resultado do encontro de aspectos biológicos com experiências de aprendizagem. Programas eficazes que propõem a aprendizagem socioemocional como parte de uma educação integral no contexto escolar podem ser implementa- 
dos nos sistemas educacionais como parte integrante da grade curricular. Assim, as habilidades são abordadas do mesmo modo que os conteúdos acadêmicos, ou seja, intencionalmente e de forma que sejam promovidas oportunidades para que haja a sua aplicação prática em diferentes atividades do dia a dia.

ACP - Para os próximos anos, com os impactos da quarta revolução industrial, da internet das coisas e a inteligência artificial, preveem-se, de um lado, a extinção de milhares de empregos e, de outro, a criação de profissões ainda nem pensadas. Nesse cenário, como fica a demanda por habilidades socioemocionais no mercado de trabalho?

GA e RP - Neste novo ambiente do século 21, a importância das habilidades socioemocionais se acentua, pois elas são capazes de ampliar o alcance de nossas ações em múltiplos contextos. De modo especial, a abertura ao novo é muito importante, pois permite que, com a nossa curiosidade intelectual, exploremos mais e aprendamos com o mundo; de forma interessada e motivada, o que nos torna permeáveis a diversidades em muitos contextos. Assim, conseguimos aprender muitas realidades e conteúdos novos. Ao lado disso, explorar e aprender com o mundo de modo colaborativo, com engajamento no trabalho em equipe e com criatividade, permitirá pensarmos juntos produtos inovadores e úteis aos contextos nos quais atuarmos.

Em um mundo cada vez mais volátil, incerto, complexo e ambíguo - o chamado "Mundo VUCA", do inglês Volatility, Uncertainty, Complexity, and Ambiguity -, são mais as habilidades socioemocionais, e menos as técnicas e acadêmicas, que justamente equipam as pessoas com ferramentas que elas podem empregar em contextos e momentos diferentes e diversificados, conforme desejarem. Como exemplo, recrutadores ouvidos para a $12^{a}$ edição do estudo Índice de Confiança Robert Half (ICRH) apontaram que valorizam mais as habilidades comportamentais, citando entre elas a adaptabilidade, a resiliência, a flexibilidade, a colaboração, a comunicação, a criatividade e a empatia. Desse modo, ao se ampliar o repertório de habilidades socioemocionais dos sujeitos, será possível recrutá-las de forma eficiente e bem-sucedida em uma variedade maior de situações, aumentando as oportunidades profissionais e favorecendo a empregabilidade.

ACP - Há, atualmente, uma importante discussão sobre a avaliação de habilidades socioemocionais na educação básica, desde a sala de aula até perspectivas em larga escala. Quais os desafios da implementação desse tipo de avaliação e os prováveis bons e maus usos que podem vir a decorrer da apropriação dos resultados pelos sistemas educacionais?

GA e RP - Por meio de uma avaliação ampla de habilidades socioemocionais dos estudantes, em que se saibam os elementos sendo avaliados com mais granularidade, é possível aos gestores educacionais fundamentar a tomada de decisão com base em evidências sobre o desenvolvimento do corpo discente e seus desafios, podendo ser uma das fontes de informação que os permitirá alocar recursos necessários conforme as diferentes vulnerabilidades contextuais, bem como planejar e avaliar prá- 
ticas mais eficazes de ensino e desenvolvimento dessas habilidades. Resultados desse tipo de avaliação sistematizada favoreceriam, portanto, uma compreensão ampla e abrangente sobre os estudantes e suas circunstâncias, permitindo observar como diferentes características se manifestam neles e, dessa forma, forneceriam evidências com vistas à concepção de políticas mais personalizadas de ensino-aprendizagem e de apoio ao fazer docente.

A avaliação, no contexto educacional, deve sempre servir a um propósito mais amplo: o de favorecer a aprendizagem, seja no âmbito da sala de aula, seja para orientar a gestão do sistema educacional sobre aspectos a serem acompanhados e que podem ajudar a conhecer melhor as diferentes realidades. Dessa forma, a avaliação pode ser um suporte adequado às escolas conforme os diferentes contextos e as idiossincrasias de cada instituição de ensino. Por outro lado, usos inadequados de resultados de processos avaliativos contribuem negativamente para a percepção equivocada de que a avaliação segrega, marginaliza e rotula os respondentes. De modo algum os resultados de avaliações podem ser compatíveis com tais propósitos, por algumas razões a saber: a) não são adequadas e suficientes para embasar políticas de responsabilização de professores, bônus ou sanção; b) não permitem traçar um perfil ideal do estudante, visto que tal perfil inexiste, dado que uma diversidade bastante ampla de características se combinam com outras variáveis; c) não devem criar rankings, também porque há uma diversidade muito grande de elementos que, apenas em conjunto com esses resultados, podem conferir-lhes a possibilidade de interpretações acuradas; d) não devem ser interpretadas como características imutáveis, uma vez que podem ser desenvolvidas; e) não se prestam a justificar ou naturalizar comportamentos, já que são multideterminados.

Assim, é muito importante que todos os atores da escola, desde aqueles que atuam nas redes de ensino, na gestão educacional, até os que atuam diretamente no contato com os estudantes, sejam devidamente formados e tenham espaços de compartilhamento de aprendizados e discussões; para que possam fazer uso qualificado, adequado e eficiente dos resultados, de modo que consigam integrar a eles outros elementos relevantes para atribuir-lhes maior sentido e garantir uma interpretação bem fundamentada. Nesse sentido, é também muito benéfico que haja a junção de esforços intersetoriais, os quais promovam o tema de forma acessível e com base em evidências. Como exemplo desse tipo de iniciativa, o Instituto Ayrton Senna, em parceria com o Conselho Nacional de Secretários de Educação (Consed), está promovendo o projeto "Volta ao Novo - Programa de Desenvolvimento de Competências Socioemocionais", para apoiar as redes de ensino com conteúdos socioemocionais, frente ao desafio das aulas a distância e a retomada das atividades escolares após o fechamento das escolas devido à pandemia da Covid-19, com ações que chegam a todo o território nacional. 
ACP - No Modelo Pedagógico Senac, as habilidades socioemocionais são desenvolvidas na articulação entre elementos de competências: conhecimentos, habilidades, atitudes e valores relacionados aos fazeres profissionais das ocupações que formamos. 0 que você diria para nossos professores em relação às possibilidades de ensino e aprendizagem e, em especial, à avaliação dessas habilidades na educação profissional?

GA e RP - É muito importante que os docentes se tornem conscientes das habilidades socioemocionais em muitos sentidos, incluindo o que são e por que são importantes. É preciso que compreendam e utilizem uma taxonomia e linguagem comum com seus estudantes, para que, então, consigam identificar e nomear, em si e nos outros, essas capacidades de modo mais eficiente. Ao lado disso, é importante que os professores também conheçam a literatura em que são relatadas técnicas em diferentes áreas que se demonstraram bem-sucedidas para a aprendizagem socioemocional.

O desenvolvimento intencional das habilidades socioemocionais em ambiente escolar é mais efetivo se ocorrer de modo sequencial, ativo, focado e explícito (SAFE), sendo necessário planejamento para que isso aconteça. Deve ser sequencial, na medida em que o desenvolvimento socioemocional precisa ser trabalhado para mobilizar cada competência, considerando situações variadas, sequenciais e cada vez mais complexas. É também ativo porque é necessária a proposição de tarefas e oportunidades concretas para o seu desenvolvimento. Do mesmo modo, é preciso ter clareza e foco quanto a quais competências socioemocionais serão trabalhadas na situação de aprendizagem. E se trata de um desenvolvimento explícito, uma vez que a aprendizagem e o desenvolvimento são favorecidos quando os objetivos estão claros e compartilhados. Isso significa que o professor deve apresentar de modo explícito as competências socioemocionais que serão desenvolvidas, promover a compreensão sobre elas, além de instaurar vocabulário comum e um campo de sentido compartilhado. Desse modo, o estudante amplia o conhecimento sobre si e sua atuação no mundo.

Para os processos de avaliação das habilidades socioemocionais, por sua vez, é necessário tanto que haja uma compreensão abrangente sobre os estudantes e seus contextos, para que a gestão escolar possa planejar suas ações com base nessas evidências, como é preciso que sejam favorecidos propósitos formativos nas avaliações nas escolas, de modo que seja possível aos docentes e alunos especificar o passo a passo do percurso de desenvolvimento, facilitando e evidenciando a elaboração ou o acompanhamento de critérios avaliativos, visando alcançar os objetivos de aprendizagem estabelecidos entre eles. É também muito interessante que esses resultados avaliativos sejam combinados, por exemplo, com os interesses profissionais dos estudantes, possibilitando-lhes entender quais pontos desejam desenvolver para evoluir em direção aos seus objetivos profissionais, o quanto se aproximam de dominar o conteúdo que está sendo desenvolvido, e regular sua própria aprendizagem. 